\title{
Testing Research on the Professional Ability of Multi-axial UAV Operators Based on Eye-movement Technology
}

\author{
Xun $\mathrm{Li}^{1, \mathrm{a}}$, Huikun Pei ${ }^{1, \mathrm{~b}}$, Fei Sha ${ }^{2, \mathrm{c}}$, Xin Zhang ${ }^{1, \mathrm{~d}}$ and Wanli Chen ${ }^{3, e^{*}}$ \\ ${ }^{1}$ Shenzhen Power Supply Co. LTD, Luohu District, Shenzhen, Guangdong, China \\ ${ }^{2}$ UAV Research Institute, BeiHang University, Haidian District, Beijing, China \\ ${ }^{3}$ Robot Research Institute, BeiHang University, Haidian District, Beijing, China \\ a42400451@qq.com, bicecood@163.com, sfflybuaa@163.com
}

Key words: multi-axial UAV, UAV flight operation, eye-movement instrument.

Abstract. Nowadays large numbers of multiaxial UAVs are applied in the civilian field. The security of operating UAV has been upped to new levels. It has now become urgent to solve the problems of training high-quality UAV operators and effectively evaluating their training results. The article attempts to introduce the eye-movement technology, which has been widely used in the aviation field, to UAV and then onto design experiments. The three measured parameters of eye-movement- the testees' eye-movement frequency, average fixation duration and the first time to fixate on the area of interest - are used as the basis for quantitative evaluation and research so as to get the data from hot spots and eye-movement rates. Through analyzing the regular patterns of the testees' eye-movements, the article preliminarily obtains the results of skill evaluation supported by quantized data by using the method of combining the eye-movement analysis technics and theories of human-factor engineering and the essential points of operating UAV.

\section{Introduction}

At present, and with a rapid development, UAV technologies have played an indispensable role in modern local wars and actions in the military field. Likewise, UAV technologies are also experiencing a booming development momentum in the civilian field. Especially in recent years, multiaxial UAV, together with the Internet, cloud computing, has become a favorite as well as a guide through modern science and technology. As for the modern-day weaponry system, humans and equipment form the two basic factors that affect the efficiency. Common scientific research mainly focuses on equipment, but plenty of failure cases force designers to increasingly take the human factor into consideration.

With the development of UAV technologies, the UAV operator has become a brand new occupation. UAV operation is the kind of work that needs high-level expertise. Through analyzing the 48 cases of the U.S. Army and Air Force that occurred between January 1993 and June 2003, 33 accidents $(69 \%)$ were caused by human factors, $27 \%$ of which were due to training problems, $25 \%$ to team efficiency, $18 \%$ to situation awareness (SA), 16\% to interface design and $14 \%$ to cognition and decision. There were 56 UAV accidents that happened in the U.S. Army from 1995 to 2003, of which $18(32 \%)$ were concerned with human factors ${ }^{[1]}$. The research report of the U.S. Air Force pointed out that the main reason for the "Predator" UAV accident had been transferred from the original hardware failure to mis-operation of the crew. Therefore, the quality level of UAV flight operators directly determines the flight security of UAV. As for civilian UAV, the quality of operators may become the short slab of the reliability and security within the overall UAV system, because civilian UAV has a low fixation point and low costs. Thus it is impossible for civilian UAV to select the suitable talent from a wide range and multiple angles, to strictly and professionally train them for a long time and to turn them into qualified UAV operators. In addition, the explosive growth of demand for civilian UAV operators has further lowered the access threshold. There is no time or money to conduct professional training. Hence, it is very alarming when it comes to the overall quality of civilian UAV operators. 
According to the reliability theory of the man-machine system, the reliability Rs of the whole system is the product of the machine reliability $\mathrm{Rm}$ and human reliability $\mathrm{Rh}^{[2]}$.

$$
\mathrm{Rs}=\mathrm{Rm} \cdot \mathrm{Rh}
$$

Therefore, it can be predicted that human reliability may become the key problem impacting on the reliability of the whole UAV system, and the biggest obstacle that restricts the secure use of civilian UAV.

The systematic and effective professional training is an efficient approach to improve the quality of UAV operators. How to evaluate the training results and scientifically, effectively identify operators' professional quality also forms an issue worth studying.

Eyes are an important channel for humans to acquire information. Some studies have shown that about $80 \%$ to $90 \%$ of our information comes in through the visual sense ${ }^{[3]}$. Eyes can reflect physiological and psychological changes in the human body. The research on eye-movement is considered as one of the most effective means in the research on visual information processing; thus the eye-movement instrument came into being. In the aviation field, the eye-movement instrument can be traced back to the 1950s when it targeted pilots and was used to evaluate the importance of new instruments, the difficulty of instrument interpretation and the arrangement of the instrument panel. In the 1960s, researchers began to study the scanning pattern of pilots. Many research models were established on the basis of eye-movement data and the support of seeking eye-movement data. By using eye-movement data, researchers could evaluate the scanning behavior of pilots and understand their process of controlling the attitude, position and movement rate of different airplanes and their process of gaining information from the instrument. The scanning analysis technics developed rapidly throughout the 1980s. This analysis technique was combined with control methods and the flight parameters of airplanes as to evaluate the displayer design ${ }^{[4]}$. In the 21 st century, the research on eye-movement technology has experienced a tremendous development within the aviation field. At present, the technology is mainly applied in the following three aspects:

1. Evaluation of man-machine efficacy;

2. Research on pilots' cognitive patterns;

3. Assessment of pilots' skills and state;

In the UAV field, as the models of UAVs show great differences, the constitution of an UAV operator group is much complicated than that of manned plane operator group. The selection and training standards of UAV operators cannot be unified; meanwhile, their levels are uneven. Naturally, it is difficult to objectively and truly evaluate their skill levels.

The article aims at the difficulties trapped in scientifically identifying the skill levels of UAV operators and the attempts at introducing eye-movement technology, which has been widely used in the aviation field, to UAV. As for the four measured parameters of the eye-movement - the four testees' eye-movement frequency, average fixation duration, fixation point sequence and their first time of fixating on the area of interest, the article gets the data from both hot spots and eye-movement rates. Through analyzing the regular patterns of the eye-movements, the article preliminarily obtains the results of skill evaluation supported by quantized data by using the method of combining the eye-movement analysis technics and theories of human-factor engineering and the essential points of operating UAV.

\section{Eye-movement Experiment Design}

Experiment Equipment. Eye-link-XX eye-movement instrument and the matched computer; Screenshots of the control interface of one particular multiaxial UAV;

First Experiment Design. The article has designed two experiments: the experiment within the eye-movement hot spot region and the seeking experiment. The former is aimed at analyzing the difference in the regional distribution of eye-movement hot spots between the operators who have received professional training and the non-professional common operators. The latter is designed to distinguish the difference of eye-movement efficiency among different operators. In the first 
experiment, the testees are requested to observe the operation interface of one particular multiaxial UAV for two minutes and record the data, respectively. No need for observation styles;

Second Experiment Design. The second experiment is design as follows:

1. A testee is required to observe the first picture again; other testees should avoid doing so. Firstly the testee voices the parameter information of the first interface. Let him/her look for 30 seconds. Afterwards, tell the testees the next parameters that should be sought out and let him/her spot them within 30 seconds. Such a seeking test shall be conducted 5 times and the data shall then be recorded. After wrapping up, another testee should replace the first one.

2. The rest 3 testees successively repeat the test procedures mentioned above and record the data.

Requirements of the Testees . Test 1: one UAV operator with professional training and three UAV operators without professional training; Test 2: three UAV operators with professional training and nine UAV operators without professional training

\section{Processing and Analyzing the Experiment Data}

Experiment of the eye-movement hot spot region. The first experiment successively records the four testees' eye-movement data of the test and creates their hot spot region map.The results is detailed shown bellow:

1) The test result of the testee (A) is shown in Fig. 1.

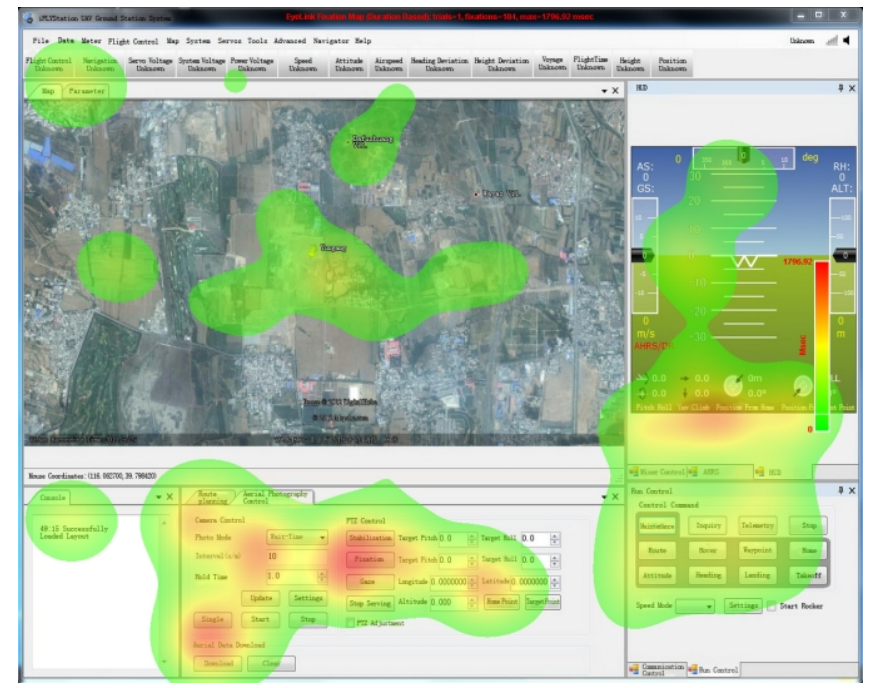

Fig. 1. Test 1 of the hot spot region

2) The test result of the testee (B) is shown in Fig. 2.

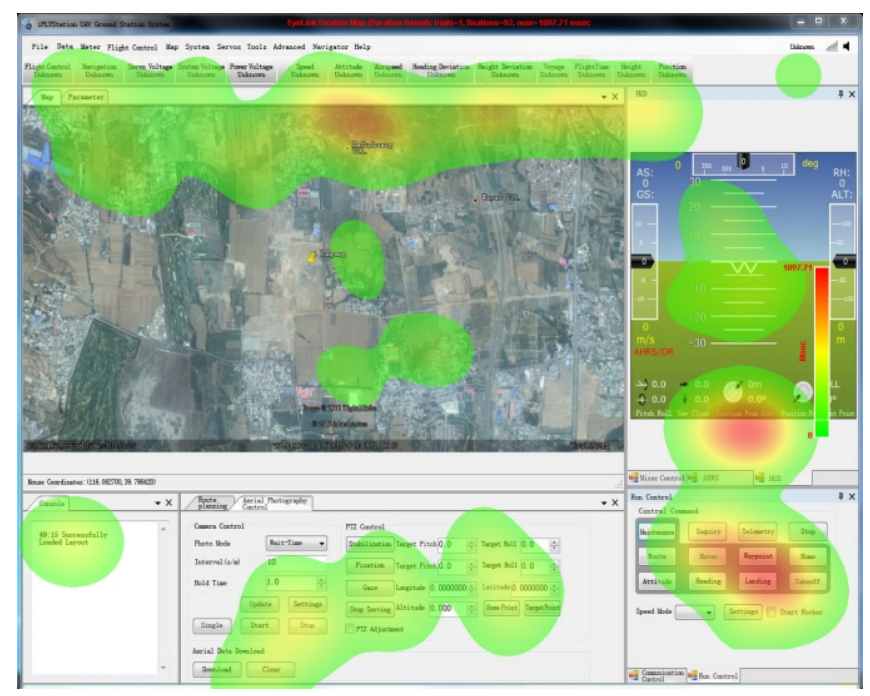

Fig. 2. Test 2 of the hot spot region 
3) The test result of the testee (C) is shown in Fig. 3.

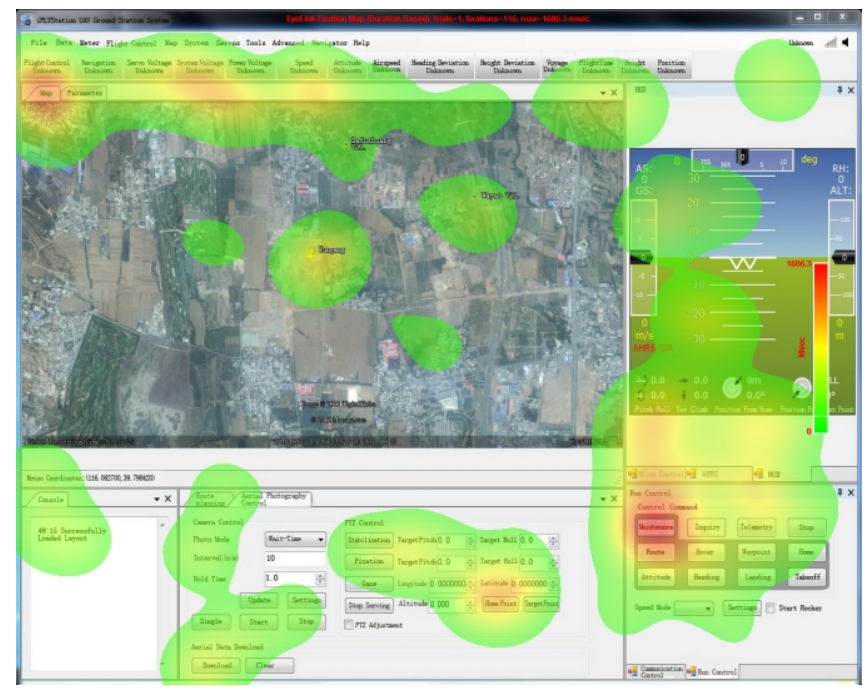

Fig. 3. Test 3 of the hot spot region

4) The test result of the testee (D) is shown in Fig. 4.

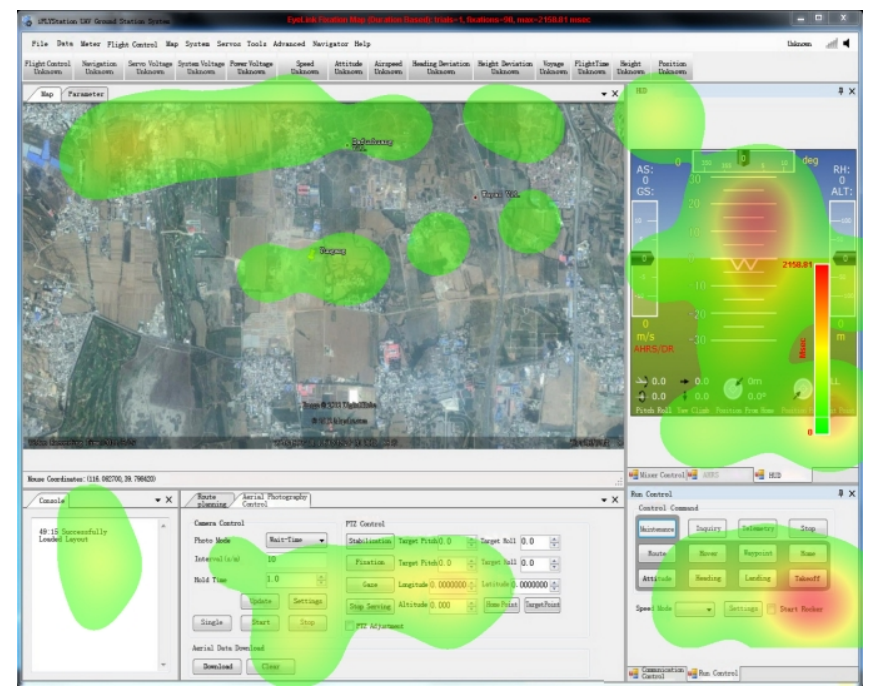

Fig. 4. Test 4 of the hot spot region

5) The statistics of the test data of the eye-movement hot spot region is shown in Table. 1.

Table. 1.The statistics chart of the test data of the eye-movement hot spot region

\begin{tabular}{|l|l|l|l|l|}
\hline \multirow{2}{*}{ No } & \multirow{2}{*}{ Name } & \multirow{2}{*}{ Identity } & Test pattern 120s \\
\cline { 4 - 5 } & & & Times of eye-movement & $\begin{array}{l}\text { Eye-movement frequency } \\
{[\text { times/s] }}\end{array}$ \\
\hline 1 & A & Non-professional & 104 & 3.47 \\
\hline 2 & B & Non-professional & 92 & 3.07 \\
\hline 3 & C & Non-professional & 116 & 3.87 \\
\hline 4 & D & Professional & 90 & 3.00 \\
\hline
\end{tabular}


It is the first time for the four testees to see the UAV control interface. Therefore, the interface is unknown to the testees, professional or non-professional. However, there are distinctly different features in the experiment. The analysis of eye-movement hot spot region is shown as follows:

1) The regions that the four testees observe are relatively dispersive, which accord to the features of observing a strange pattern. The testees should have a general understanding of the overall situation in the beginning;

2) The common feature of the four testees lies in the fact that they are not interested in Google Maps and that they can ascertain through several glances that there is not much useful information to be taken away from the map;

3) The interest points for each testee are different: $\mathrm{A}$ is sensitive to digital information; the eye-movement rate of $\mathrm{B}$ is relatively low and he prefers to pay attention to details; $\mathrm{C}$ habitually pays attention to the information in the upper-lift corner, for the information in the upper-lift corner is usually the region of partitioning the functions of a software interface;

4) Facing the same unknown picture, the fourth testee shows distinct differences from other three ones: the eye-movement rate of D is 3.0, the lowest among the four testees. Nevertheless, he is able to extract more useful information than others, which is specifically reflected in the fact that his attention to unimportant information is all green. This proves that his way of reading information is to lower the eye-movement rate, read the information once only and quickly to make a judgment. However, the others' way of reading is aimed to improve eye-movement rate and absorb the information several times. Moreover, due to professional knowledge, they cannot accurately distinguish important from unimportant information;

5) The most important information in the picture is concentrated in the right and upper parts (the flight dial plate on the upper right, flight control instructions and parameters on the bottom right, important telemetry parameters on the upper part). D's grasp of useful information is the most accurate and his principal force focuses on the flight dial plate;

As the character font is relatively small at the bottom of the interface, all four testees slow down their identification process across this region, specifically reflected in the aspect the red hot spot region appears in the bottom of all testees' test pictures.

Seeking Experiment. The testees are required to seek for five parameters in the operation interface within 30s: AS $\rightarrow$ system voltage $\rightarrow$ rotating speed $\rightarrow$ take off $\rightarrow$ angle of pitch.

The data statistics of the seeking experiment is shown in Table. 2. 
Table. 2. Data sheet of the seeking experiment

\begin{tabular}{|c|c|c|c|c|c|c|c|c|c|c|c|c|c|c|}
\hline \multirow{2}{*}{ No } & \multirow{2}{*}{ Identity } & \multicolumn{5}{|c|}{ Times of eye-movement } & \multirow{2}{*}{$\begin{array}{l}\text { Averag } \\
\text { e times }\end{array}$} & \multicolumn{5}{|c|}{ Eye-movement time [s] } & \multirow{2}{*}{$\begin{array}{l}\text { Average } \\
\text { time }\end{array}$} & \multirow{2}{*}{$\begin{array}{l}\text { Eye-mov } \\
\text { ement } \\
\text { rate }\end{array}$} \\
\hline & & 1 & 2 & 3 & 4 & 5 & & 1 & 2 & 3 & 4 & 5 & & \\
\hline 1 & $\begin{array}{l}\text { Non-profess } \\
\text { ional }\end{array}$ & 62 & 35 & $\begin{array}{l}9 \\
0\end{array}$ & 68 & $\begin{array}{l}11 \\
5\end{array}$ & 74 & 25 & 16.7 & $\begin{array}{l}28 . \\
4\end{array}$ & 19.2 & 27.3 & 23.3 & 3.08 \\
\hline 2 & $\begin{array}{l}\text { Non-profess } \\
\text { ional }\end{array}$ & 74 & 17 & $\begin{array}{l}7 \\
1\end{array}$ & 21 & 68 & 50.2 & $\begin{array}{l}19 . \\
6\end{array}$ & 4.3 & $\begin{array}{l}20 . \\
5\end{array}$ & 6.8 & 20 & 14.2 & 3.54 \\
\hline 3 & $\begin{array}{l}\text { Non-profess } \\
\text { ional }\end{array}$ & 30 & 42 & $\begin{array}{l}7 \\
6\end{array}$ & 129 & $\begin{array}{l}12 \\
5\end{array}$ & 66.4 & 8.6 & 10.3 & $\begin{array}{l}19 . \\
1\end{array}$ & 30.1 & 30.1 & 19.6 & 3.39 \\
\hline 4 & Professional & 4 & 7 & 8 & 4 & 6 & 5.8 & 1.0 & 1.4 & 1.2 & 0.8 & 1.2 & 1.1 & 5.27 \\
\hline 5 & $\begin{array}{l}\text { Non-profess } \\
\text { ional }\end{array}$ & 45 & 66 & $\begin{array}{l}3 \\
1\end{array}$ & 93 & 80 & 63 & $\begin{array}{l}20 . \\
3\end{array}$ & 22.6 & 8.5 & 30.1 & 25.2 & 21.3 & 2.96 \\
\hline 6 & $\begin{array}{l}\text { Non-profess } \\
\text { ional }\end{array}$ & 49 & 92 & \begin{tabular}{|l|}
6 \\
6 \\
\end{tabular} & 34 & 95 & 67.2 & $\begin{array}{l}26 . \\
4 \\
\end{array}$ & 23.8 & $\begin{array}{l}30 . \\
1\end{array}$ & 12 & 30.1 & 24.5 & 2.74 \\
\hline 7 & $\begin{array}{l}\text { Non-profess } \\
\text { ional }\end{array}$ & 22 & 88 & $\begin{array}{l}4 \\
4 \\
\end{array}$ & 91 & 90 & 67 & 7.3 & 30.1 & $\begin{array}{l}15 . \\
2\end{array}$ & 28.6 & 27.8 & 21.8 & 3.07 \\
\hline 8 & Professional & 6 & 3 & 5 & 8 & 5 & 5.4 & 1.3 & 0.7 & 0.9 & 1.5 & 1.1 & 1.1 & 4.91 \\
\hline 9 & $\begin{array}{l}\text { Non-profess } \\
\text { ional }\end{array}$ & 32 & 97 & \begin{tabular}{|l}
3 \\
6 \\
\end{tabular} & 14 & 95 & 54.8 & 10 & 30.1 & $\begin{array}{l}13 . \\
4\end{array}$ & 4.9 & 27.7 & 17.2 & 3.19 \\
\hline 10 & $\begin{array}{l}\text { Non-profess } \\
\text { ional }\end{array}$ & 83 & 85 & \begin{tabular}{|l|}
7 \\
8 \\
\end{tabular} & 96 & 16 & 71.6 & \begin{tabular}{|l}
25. \\
1 \\
\end{tabular} & 27.4 & $\begin{array}{l}21 . \\
2\end{array}$ & 29.6 & 6.6 & 22.0 & 3.25 \\
\hline 11 & $\begin{array}{l}\text { Non-profess } \\
\text { ional }\end{array}$ & 9 & 46 & $\begin{array}{l}3 \\
2\end{array}$ & 94 & 92 & 54.6 & 2.8 & 15.3 & $\begin{array}{l}11 . \\
4\end{array}$ & 30.1 & 27.8 & 17.5 & 3.12 \\
\hline 12 & Professional & 12 & 7 & 8 & 6 & 3 & 7.2 & 2.5 & 1.0 & 1.0 & 1.2 & 0.7 & 1.3 & 5.54 \\
\hline
\end{tabular}

Whereas the differentiation between professional and non-professional operators is not very clear or outspoken from the former hot spot region test, the differences in professional quality are clearly reflected in the seeking experiment. The seeking experiment analysis is shown as follows:

1) Longitudinal comparison: the eye-movement of $D$ has remarkably improved (from 3.0 to 5.27) when compared with that in the hot spot region test, for this is usually where problems occur or operation is required when the testee must seek out the parameters of a certain feature. At the moment, D is usually nervous and will react quickly. By contrast, the eye-movement rate of the other three non-professional operators does not show any remarkable changes when compared with that of the hot spot region test.

2) Transverse comparison: the average times of seeking eye-movement of the non-professional operators are 63.511 times that of the professional operators. Their average seeking time is 17.6 seconds 17 times that of the professional operators. Therefore, the gap is highly remarkable.

\section{Conclusions}

The following conclusions have been reached after analyzing and comparing the two eye-movement experiments:

1. Professional training has significant influences upon improving the professional quality of operators; 
2. There are differences in the eye-movement data of different individuals, which also reflect how there are individual differences in various aspects of psychological conditions, knowledge levels, hobbies and interests;

3. The significance of professional training is reflected not only in the realization of a single purpose, but also in the accompanying functions, that is, professional training can impose positive influences on the professional skills of trainees in a certain kind or a field.

After analyzing the design quality of the operation interface through the differences in the eye-movement hot spot region, the article has drawn the following conclusions and summarized a few regular things used to guide the design of such interfaces:

1. The design style and form of the tested interface adopted are liable to attract attention. Although the most important flight dial plate and instruction parameters of the picture are located to the right (according to the theories of human-machine engineering -- important displays shall be arranged towards the middle or the upper left), they still draw the attention of the four testees;

2. In the interface where there are more Chinese characters, acronyms and digital information are more attractive;

3. Warning colors, such as red, orange, etc. are more likely to grab people's attention;

4. Contrary to what has been assumed previously, some graphic information does not attract the testees' attention. The reason for this, which has been tentatively speculated about, is that on the one hand, the testees have a strong purpose; on the other hand, the testees are all engineering postgraduates and maybe their interest points are different from those of ordinary people.

\section{Discussion regarding some problems}

There are mainly two problems with the experiment.

The problem of sample sizes. There are four testees in the eye-movement hot spot region test. The sample size is so low that it influences the statistics of the test data. There may also be some deviations within the accuracy of the statistics result data.

The problem of test design. It has been found that there are several problems occurring in the test design after practicing. For example, the seeking experiment was initially designed to incessantly seek for and test out five parameters. It turns out that the test data are so chaotic that it is difficult to extract and effectively deduct intervals. Thus the experiment accuracy is influenced. Although we have modified later, similar problems still exist. The reasons for these problems are two-fold: on the one hand, the time span is too short to make full preparations; on the other hand, the level of the test designers is limited, thus they cannot realize further mechanism problems.

\section{Reference}

[1] Schmidt J, Parker R Development of a UAV mishap human factors database[C / OL] / Association for Unmanned Vehicle Systems International. Unmanned Systems 1995 Proceedings, Washington. DC, 1995 [2010-03-11].

[2] Long Shengzhao, etc. Research on the Evaluation Methods of the Reliability and Security of the Human-machine-environment System, Research Report, Institute of Space Medico-engineering, 1996 (In Chinese).

[3] Sun Ruishan, Chen Nongtian. Progress of Eye Analysis Techniques and Its Application in Aviation, Journal of Civil Aviation University of China, 2009, 8 (In Chinese).

[4] THOMAS SCHNELL, YONGHN KWON, SOHEL MERCHANT. Improved flight technical performance in flight decks equipped with synthetic vision information system displays [J]. The International Journal of Aviation Psychology, 2004, 14 (1): 79-102. 